\title{
Desafios para a implantação da Educação Integral: análise das experiências desenvolvidas na região sul do Brasil
}

\section{Challenges for the implementation of the Integral Education: analysis of the experiments conducted in southern Brazil}

\author{
Veronica Branco ${ }^{1}$
}

\begin{abstract}
RESUMO
Este texto trata da percepção dos gestores municipais, coordenadores pedagógicos e pais de alunos sobre os desafios enfrentados para a implantação da Educação Integral ou do aumento de tempo da jornada escolar em experiências desenvolvidas na região Sul do Brasil: Apucarana, Joinville e Porto Alegre. Essas experiências fazem parte da pesquisa realizada pelas universidades federais: UFMG, UNIRIO, UFPR e UNB, com o objetivo de mapear experiências de jornada escolar ampliada em andamento no Brasil, no ano de 2008 - estudo quantitativo. Em 2009 e 2010 deu-se a continuidade da pesquisa, agora como estudo qualitativo. $\mathrm{Na}$ etapa do estudo qualitativo foram selecionadas vinte e uma experiências de todo o Brasil para serem acompanhadas e documentadas in loco. Na região sul foram selecionadas três experiências, uma de cada estado da região sul. Dessa etapa é que foram extraídos os dados coletados em entrevistas com os personagens citados, cujas análises compõem este texto e apontam como principais desafios/dificuldades para a implantação do aumento do tempo da jornada escolar, entre outras, a formação inicial e continuada de professores e a integração de monitores e novos atores na equipe de trabalho escolar. Além dessas aparece, fortemente marcada, no ideário dos entrevistados a concepção de que a Educação Integral é um direito das famílias e não dos alunos, e uma modalidade escolar destinada aos alunos cujas famílias são carentes e não podem atender seus filhos.
\end{abstract}

Palavras-chave: desafios; Educação Integral; gestores municipais.

1 Doutora em Educação pela Universidade Federal do Paraná (UFPR), Professora Associada no Setor de Educação da Universidade Federal do Paraná, Brasil. E-mail: veronica_branco@ hotmail.com. 


\begin{abstract}
This text is about the perception of municipal administration, pedagogical coordinators and parents of students about the challenges to introduce the Whole Education or the increasing of time of scholar journey in experiences developed in cities of the south region of Brazil: Apucarana, Joinville and Porto Alegre. These experiences are part of a research made by the federal universities: UFMG, UNIRIO, UFPR and UNB, with the purpose of mapping experiences of increased scholar journeys in process in Brazil, in the year of 2008 - quantitative study. In 2009 and 2010 there was the continuation of that research, then as a qualitative study. In the part of the qualitative study there were chosen twenty-one experiences from the whole country to be followed and documented in their place. In the south region three experiences were selected, one from each state of the region. In this phase the data was collected in interviews with the related people, whose analyses compose this text and point as main challenges/difficulties to establish the increasing time of scholar journey in the initial and continuous forming of teachers and the integration of monitors and new actors in the group of scholar tasks. Beyond these, it appears, strongly marked in the ideas of the interviewed people, the conception that the whole education is a right of the families, and not of the students, and also a kind of school dedicated to the students whose families are poor and can't take care of their children.
\end{abstract}

Keywords: challenges; Integral Education; municipal administration.

Os ideais da Educação Integral não são novos entre os educadores brasileiros. Eles aparecem na história da educação, no período da segunda república, com o Manifesto dos Pioneiros, em 1932. O documento coloca em discussão a reconstrução da educação, bem como a organização de um sistema escolar único, laico, público e obrigatório para todos, onde cada um tivesse a oportunidade de se desenvolver integralmente. Entre os signatários desse documento estava Anísio Spínola Teixeira, que foi além das discussões e críticas ao ensino então existente.

Falar de Educação Integral no Brasil nos obriga a acompanhar um pouco a história das realizações desse educador.

Nos anos de 1931 a 1935, Anísio Teixeira assumiu a Diretoria de Instrução Pública do então Distrito Federal, e elaborou para o Rio de Janeiro um arrojado projeto educacional. Dentre as reformulações propostas pelo educador, Coelho e Cavalière (2002) destacam "a criação de divisões de prédios e aparelhamentos escolares e das bibliotecas e cinemas educativos e do instituto de pesquisas" como uma marca de sua preocupação "com as instalações escolares, com a área cultural como um todo e com o estudo e pesquisa de novos métodos de ensino" (COELHO; CAVALIÈRE, 2002, p. 48). 
Desejando concretizar o projeto educacional desenhado para o Rio de Janeiro Anísio Teixeira instalou cinco escolas experimentais para servirem de laboratório, para ensaiar e experimentar novos métodos de ensino que pudessem sustentar as mudanças desejadas em todo o sistema educacional do Distrito Federal. Não se tratavam de Escolas de Tempo Integral, eram escolas idênticas às demais, porém tinham como grande diferencial, tal como nos reporta seu criador:

o propósito de ensaiar integralmente um novo método, nos estudos e debates que ali se realizam e na atitude experimental dos professores, que examinam, ensaiam, verificam os resultados e estão sempre prontos a suspender os julgamentos, a reexaminar o problema e a estudar e reestudar continuamente os processos de ensino e educação (TEIXEIRA, 1930, p. 203).

Além disso, eram escolas em que a semente da Educação Integral se fazia presente através de uma nova organização do currículo, com o aumento das disciplinas e com a incorporação de novos espaços como: jardins e parques recreativos, salas especiais para o ensino de desenho e música, laboratórios, auditórios e a preocupação com a formação para o trabalho com a incorporação de oficinas de carpintaria e mecânica.

Retornando à Bahia, e assumindo o posto de Secretário Estadual de Educação, Anísio ousou implantar, na periferia de Salvador, um modelo de escola que ele denominou de Tempo Integral, "com o currículo mais completo possível" (ÉBOLI, 1969): no Centro Educacional Carneiro Ribeiro, tal como o apresentou no discurso de inauguração do complexo escolar, em 1950:

Um programa completo de leitura, aritmética e escrita, ciências físicas e sociais, artes industriais, desenho, música, dança, educação física. Além disso: desejamos que a escola eduque, forme hábitos, forme atitudes, cultive aspirações, prepare realmente a criança para sua civilização - essa civilização técnica e industrial e ainda mais e, além disso, desejamos que a escola dê saúde e alimento à criança, visto não ser possível educá-la no grau de desnutrição e abandono em que vive (EBOLI, 1969, p. 16).

O modelo educacional de Anísio Teixeira era composto por quatro Escolas-Classe, onde cerca de 500 alunos em cada uma delas recebiam em um turno 
o ensino dos conteúdos tradicionais e, no contraturno, almoçavam na Escola Parque e participavam de atividades culturais, esportivas, artísticas, sociais e de iniciação ao trabalho. Além das atividades escolares os alunos recebiam atendimento médico e odontológico. O complexo da Escola Parque atendia mil alunos por turno.

Deixando a Bahia, a convite do Presidente Jucelino Kubistchek de Oliveira, Anísio Teixeira juntou-se a outros notáveis da educação, entre eles Darcy Ribeiro, para projetar o modelo de educação para o Brasil na futura capital - Brasília. Lá também ele deixou a marca de seu ideal de Escola em Tempo Integral, com a construção de um complexo escolar de uma Escola Parque e Escolas-Classe.

No entanto, a necessidade de multiplicar a oferta de vagas nas escolas para cerca de $50 \%$ da população em idade escolar, que no final dos anos 50 do século XX ainda não tinha acesso ao sistema de ensino público, fez com que os governos optassem por ofertar o ensino em dois e até três turnos diários, por escola. Dessa forma, a ampliação da jornada escolar e do currículo mais completo caiu no esquecimento dos governantes.

Nos anos 80 do século XX, o ideário de Anísio Teixeira de escola em Tempo Integral que oferecesse a oportunidade de desenvolvimento integral é retomado por Darcy Ribeiro, na cidade do Rio de Janeiro, com a construção dos Centros Integrados de Educação Pública (CIPEs).

A partir dos anos 90 do século XX vão aparecendo pelo Brasil experiências de Tempo Integral e outras de Educação Integral inspiradas no ideário de Anísio Teixeira e Darcy Ribeiro. São em sua maioria experiências organizadas pelos municípios e não seguindo um projeto político mais amplo, continuado e de governo.

\section{A Concepção contemporânea de Educação Integral}

No entanto, é somente em 2007, com o advento da Portaria Interministerial $n^{\circ} 17$ e, posteriormente, com o Decreto Presidencial $n^{\circ} 7.083 / 2010$, que o governo federal assume uma política indutora focando fortemente a implantação da Educação Integral nas escolas públicas brasileiras, tendo como principal objetivo garantir a aprendizagem de todos os alunos.

A ampliação da jornada escolar ao colocar em questão o tempo de permanência dos alunos sob responsabilidade da escola, dentro ou fora dela, destaca não mais o tempo para o ensino e sim o tempo para a aprendizagem.

Enguita (2006), observando o contexto espanhol, comenta que o tempo escolar foi estabelecido tendo em vista a concepção de educação das gerações e 
do contexto sociopolítico e econômico de sua época, embora pareça que a jornada escolar sempre esteve determinada e não possa ser mudada sem que se prove, com sólidos argumentos, a razão para tal. O autor, acompanhando a história dos tempos escolares, aponta que o que se verifica é que na concepção predominante, a da transmissão, eles foram estabelecidos com vistas ao tempo necessário para que o professor transmitisse seu ensinamento. E esse mesmo conceito de tempo é que determinou a carga horária de trabalho dos professores. No entanto, a constatação de que o aumento das horas de trabalho dos pais, e principalmente a maior inserção das mães no trabalho fora do lar, evidenciou a necessidade da escola estender o tempo de atendimento às crianças. Seja como for, o aluno e sua aprendizagem só agora vai assumindo peso significativo nessa mudança.

\section{$O$ contexto da pesquisa}

Procurando levantar, entre outras questões, as razões do aumento de tempo da jornada escolar no Brasil, em execução em 2008, é que o Ministério da Educação solicitou uma pesquisa a um consórcio de universidades: Universidade Federal do Paraná (UFPR), Universidade Federal do Estado do Rio de Janeiro (UNIRIO), Universidade Federal de Minas Gerais (UFMG) e Universidade Nacional de Brasília (UnB).

A pesquisa deu origem a este texto e teve seu inicio em 2008 com a etapa de coleta de dados de natureza quantitativa, que permitiu a identificação das experiências de jornada ampliada (MINISTÉRIO DA EDUCAÇÃO, 2008/2009) desenvolvidas pelos municípios brasileiros dentre os respondentes.

$\mathrm{O}$ instrumento de coleta de dados forneceu um grande número de informações dos municípios como: número de alunos envolvidos na experiência, atividades desenvolvidas, duração da jornada diária e semanal, professores e demais atores responsáveis pela organização e execução das atividades, turnos de execução, legislação que regulamenta a jornada ampliada das atividades escolares, a existência de parceiros, fonte de recursos que financiaram as atividades, entre outros.

Essas informações possibilitaram a identificação e a seleção das experiências que poderiam ser mais significativas para a etapa qualitativa.

A equipe de pesquisadores da Universidade Federal do Paraná, com responsabilidade de execução da pesquisa na região sul, selecionou uma experiência de cada estado da região. No Estado do Paraná foi selecionada a experiência do município de Apucarana por se tratar de uma experiência desenvolvida em tempo 
integral, conforme o tempo referencial estabelecido pela portaria interministerial $\mathrm{n}^{\mathrm{o}} 17$ de 2007, e pelo decreto presidencial $\mathrm{n}^{\mathrm{o}} 7.083 / 27 / 01 / 2010$; por envolver todos os alunos de 36 das 37 escolas da rede municipal, e também por ser, naquele momento, a de maior tempo em execução no Estado do Paraná (108 meses, nove anos), o que nos levou a considerar como sendo uma experiência com maior consolidação do trabalho. Além desses fatos, o desempenho alcançado pela rede municipal e medido pelo Índice de desenvolvimento da qualidade da Educação Básica (IDEB) em 2005, foi de 4,5 e em 2007, foi de 5,3, valores esses superiores à média do Estado e do Brasil, o que foi relevante para essa inclusão.

Do Estado de Santa Catarina foi selecionada a experiência desenvolvida em 10 escolas rurais, em tempo Integral, pelo município de Joinville. Essa experiência chamou a atenção por se tratar da única experiência rural dentre todos os municípios da região sul que participaram da fase quantitativa da pesquisa. O município de Joinville também apresenta um bom nível de qualidade da educação, pois atingiu um IDEB de 5,0 em 2005 e 5,5 em 2007, índice também superior à média nacional.

O município de Joinville mantém em sua rede uma Escola Agrícola para alunos de $5^{\mathrm{a}}$ a $8^{\mathrm{a}}$ séries, e as crianças egressas dessas escolas rurais tinham vagas garantidas na mesma, sendo que as vagas são muito disputadas por se tratar de uma escola também em tempo integral e que desenvolve um extenso currículo voltado para as atividades agrícolas.

No Estado do Rio Grande do Sul foi selecionada a experiência desenvolvida pelo município de Porto Alegre denominada Projeto Cidade Escola.

O Estado do Rio Grande do Sul apresentou o maior número de experiências de aumento de tempo de jornada escolar realizadas na região sul, embora muitas delas possam ser consideradas consolidadas, em execução há mais de dez anos, a maior parte delas não se caracteriza como sendo de tempo integral. Isso porque elas aumentam a jornada escolar em tempo inferior a 35 horas semanais (atendimento dos alunos em sete horas diárias, em cinco dias da semana), conforme prevê a legislação pertinente, ofertando em média um aumento de no máximo 10 horas semanais.

O site da Secretaria de Educação de Porto Alegre apresenta informações sobre o Projeto "Cidade Escola", onde consta que os disparadores do Projeto "Cidade Escola" foram a preocupação com um novo formato de escola que contemple as necessidades e desejos dos alunos e a constante busca pela qualificação do ensino na rede municipal”.

O mesmo site acrescenta que:" "o conceito de Cidade Escola enfatiza a interação e a transversalização entre as ações da Cidade e da Escola, possibilitando ao aluno desenvolver identidade comunitária no seu bairro-escola ao mesmo tempo em que se apropria e é acolhido por variados espaços da cidade" (PREFEITURA DE PORTO ALEGRE, 2008). 
As atividades de aumento da jornada escolar são realizadas no contraturno dos alunos, dentro de Núcleos de Atendimento, e são gerenciados por professores da rede municipal. Os enfoques dos Núcleos são determinados avaliando-se interesses e vontades da comunidade escolar.

As atividades que encontramos em desenvolvimento foram: Núcleos de Letramento, Música, Teatro, Artes Plásticas, Informática e Esporte.

Soubemos, na mesma fonte, que o "contraturno de atividades não é obrigatório e não tem carga horária pré-determinada". (PREFEITURA DE PORTO ALEGRE, 2008). A participação dos alunos é voluntária e eles se inscrevem na Equipe de Supervisão da Escola, onde têm preferência os alunos em situação de risco social e educacional. Os alunos organizam seu horário com a Equipe de supervisão da Escola.

A Secretaria informa ainda, no mesmo site, que o Projeto prevê atendimento aos três ciclos incluindo a Educação de Jovens e Adultos, (EJA).

Fomos informados por uma assessora da Secretaria de Educação que existem diferentes projetos nas 10 escolas que estão hoje (2007/2008) vinculadas ao Programa "Cidade Escola", sendo que o trabalho ocorre tanto no interior da escola quanto nos aparelhos culturais, sociais e de lazer públicos da comunidade e da cidade. A decisão do horário e do número de horas em que se realizam os projetos, também varia de acordo com os projetos de cada escola, que são discutidos com os pais dos alunos.

$\mathrm{Na}$ visita realizada a algumas das escolas que desenvolviam o Projeto Cidade Escola, em Porto Alegre, constatamos que algumas delas tinham aderido ao Projeto Mais Educação e realizado uma fusão dos dois programas, o que lhes permitiu atender um número maior de alunos e oferecer maior número de atividades diversificadas.

\section{A Educação Integral em Apucarana}

A rede pública de educação municipal de Apucarana oferta, desde 2001, a Educação em Tempo Integral para todos os alunos, da $1^{\text {a }}$ à $4^{\mathrm{a}}$ série do Ensino Fundamental. A duração do período escolar é de 9 horas diárias ininterruptas: das 7:30 às 16:30, de segunda a sexta-feira, em regime de contraturno, sendo que as oficinas são ofertadas no período da tarde.

$\mathrm{Na}$ visita à rede de escolas do município de Apucarana entrevistamos o Secretário de Desenvolvimento Humano, responsável pela educação do município, bem como os coordenadores pedagógicos, professores e pais de alunos da rede pública.

O Secretário foi responsável pelo acompanhamento da implantação do Tempo Integral nas escolas do município e nos informou que a implantação dessa 
modalidade de ensino foi resultado de uma promessa de campanha do prefeito eleito em 2000. A justificativa para essa implantação foi o conhecimento da experiência de Educação em Tempo Integral implantada, anteriormente, na cidade de Pato Branco, cidade situada no sudoeste do Paraná, cujos resultados foram muito expressivos. O desejo de implantar a Educação em Tempo Integral em Apucarana também foi decorrente de informação de experiências realizadas em outros países.

O que se verificou na fala do Secretário foi o compromisso social das autoridades municipais em relação ao bom desenvolvimento dos alunos da rede pública, em tão alto grau que assumiu a implantação da Educação Integral sem contar com boas condições de infraestrutura e de recursos humanos.

Os professores da rede municipal são concursados com padrão de 20 horas semanais e se responsabilizam pelos conteúdos do currículo formal. Para trabalhar com as atividades/oficinas no período complementar, inicialmente foram utilizadas estagiárias da Escola Normal, que ajudavam as professoras. Também foram convocadas pessoas voluntárias que tivessem habilidades de artesanato para desenvolverem oficinas. Dessa forma as oficinas não tiveram, de início, uma programação prévia e sua definição dependia das habilidades encontradas nas estagiárias para trabalharem com os alunos, conforme se depreende da fala do Secretário Municipal do Desenvolvimento Humano:

Daí nós tivemos umas estagiárias que ajudavam as professoras na sala. Alunas do Magistério... elas não tão formadas então elas vêm e ajudam daí elas falavam assim ... eu sei fazer vagonite e daí a professora Edileuza; você empresta então tá bom e aí começou e as duas foram ensinando para as crianças... e todas as crianças hoje em dia fazem vagonite... é como você colocou... num adianta só querermos professores formados pra tudo, porque não tem e nunca vai existir, né? Mas existe sim a boa vontade do professor em querer aprender, querer fazer as coisas darem certo (MINISTÉRIO DA EDUCAÇÃO, UFPR, 2010, p. 21).

O trabalho desenvolvido pelas estagiárias não foi satisfatório porque elas não se comprometiam efetivamente. Assumiam o trabalho e não compareciam com regularidade, e até mesmo deixavam de comparecer sem dar qualquer satisfação à escola, fazendo com que as oficinas não tivessem uma regularidade de funcionamento, como se deduz da fala o Secretário:

Então umas ficavam uma semana, olhavam, as crianças não gostavam, iam embora, não avisavam a gente... Desistiam sem avisar... Eram estagiárias... meninas assim de quinze, dezesseis anos. Então a gente 
sofreu muito com isso por causa dessas atitudes das estagiárias [...] Não tinha um quadro estável de tarde (MINISTÉRIO DA EDUCAÇÃO, UFPR, 2010, p. 21).

Diante dessa situação, as escolas procuraram levantar as habilidades artesanais das próprias professoras para oferecerem as oficinas. Essa foi a alternativa para que as oficinas ofertadas no período da tarde tivessem continuidade e regularidade como se refere o secretário:

Não tinha um quadro estável à tarde. Então o sonho era esse, era fazer com que o período da tarde também fosse... ficasse estável, porque de manhã era tranquilo, então as minhas professoras da manhã elas chegavam, dava aula e a gente queria que de tarde também fosse assim (MINISTÉRIO DA EDUCAÇÃO, UFPR, 2010, p. 21).

As professoras também relataram que no início da implantação do tempo integral elas se reuniam, após o período escolar e nos finais de semana, para fazer o planejamento das atividades. Dessa informação se pode deduzir que o investimento do município na formação continuada dos professores não tenha sido o suficiente porque contou com um tempo extra dos mesmos, não remunerado, para a realização de estudos e planejamento. Planejamento esse que poderia ou não ser feito, uma vez que dependia do tempo extra dos professores.

A grande preocupação das professoras é com a continuidade dos estudos dos alunos ao concluírem a quarta série. Afirmaram que os alunos estão na entrada da adolescência e justamente nessa hora ficam soltos na rua, indagam por que o estado (responsável pela oferta de $5^{\mathrm{a}}$ a $8^{\mathrm{a}}$ séries) não se preocupou em atender os alunos de Apucarana em tempo integral, desperdiçando o que o município investiu na cultura da permanência dos alunos em tempo integral. Comentaram que começar a Educação Integral só na $5^{\mathrm{a}}$ série é muito difícil e que seria muito mais fácil se o Estado se integrasse com o município para colocar as crianças que já vêm desde a primeira série em tempo integral para que tivessem uma continuidade.

Foram ouvidos quatro mães e um pai de alunos das escolas municipais. Todos afirmaram gostar muito das escolas e que seus filhos eram muito bem atendidos. Das mães ouvidas duas delas eram trabalhadoras, fora do lar, e afirmaram que ficavam tranquilas no trabalho sabendo que as crianças estavam bem cuidadas na escola. As outras duas mães que permaneciam em casa o dia todo afirmaram que gostavam muito da escola e do atendimento de seus filhos, porém 
achavam que o tempo integral era necessário só para as mães que trabalham. Para as que ficam em casa o dia todo, seria melhor que seus filhos não ficassem o dia todo na escola, uma vez que elas podem cuidar deles. Da mesma opinião foi o pai que, por ser aposentado, achava que seu filho não precisava ficar o dia todo na escola, embora ele afirmasse gostar do que o filho aprendia na escola.

A fala dos pais demonstra que a primeira preocupação deles é com o cuidado e a segurança dos filhos. Eles reconhecem que a escola oferece isso, porém não parecem compreender que permanecer na escola em tempo integral pode significar vivenciar um currículo mais amplo com maiores oportunidades de desenvolvimento de atividades educativas para os filhos. A oportunidade de participar de atividades esportivas, artísticas e culturais, desenvolvidas no tempo integral, não parece ser importante, mesmo que a maioria dos pais da escola pública não possa oferecer essas atividades a seus filhos de forma suplementar. Para eles a escola de quatro horas por dia é suficiente, é aquela que fez parte de suas vivências escolares.

Considerando que esses pais foram chamados para participar das entrevistas por serem mais atuantes na escola e por participarem da Associação de Pais e Professores da Escola, eles parecem estar pouco informados da importância do tempo integral como um direito do aluno de aprender e não apenas de tranquilidade para os pais.

Os técnicos educacionais foram indagados sobre como se deu a participação deles no Projeto de Tempo Integral e obtivemos a resposta de que esse projeto era promessa de campanha do então prefeito do município, fato já confirmado pelo Secretário de Desenvolvimento Humano, que após tomar posse colocou em execução sua promessa. Os professores não participaram dessa decisão, apenas foram convocados a participar, como afirma a pedagoga de uma das escolas:

Na verdade quando, em dois mil e um nós estávamos na escola ensinando, eu trabalhava na coordenação da escola, assim quando o prefeito lançou o ensino fundamental integral era uma promessa de campanha, né? Então a gente já tinha, assim, uma certa familiaridade com a proposta, mas assim, dizer que nós participamos com a decisão, nós temos que ser franco, que não, mas nós assumimos. Assim como responsabilidade nossa também, quando nos cobram. Né? Eu falo assim por que a minha escola onde eu trabalhava ela foi uma das primeiras que implantou o tempo integral. E o trabalho foi assim: houve momentos bons, mas houve também muitos problemas, principalmente com os pais, né? Aceitação da comunidade. Bem contrário do que é hoje, né? Porque hoje é contrário, hoje quando fala que não vai ter o tempo integral o pessoal reage em defesa dele (MINISTÉRIO DA EDUCAÇÃO, UFPR, 2010, p. 23-24). 
Embora os professores não tivessem participado da elaboração do projeto, eles assumiram sua execução, e mesmo com muitas dificuldades, conseguiram que a comunidade e os pais abraçassem o projeto.

Também os professores se sentiram desafiados e sem saber como enfrentar as novas atividades nas escolas, e então foi preciso muito apoio dos técnicos da Secretaria e do próprio prefeito, que sempre estava junto com a equipe técnica para apoiar e para ajudar a solucionar as dificuldades inesperadas, como informa uma pedagoga da secretaria:

De início também, né? teve vários encontros, né? As coordenadoras, os secretários também, tudo serve de ação, de orientação... também parte dos diretores e coordenadores ajudavam sobre como devia proceder na parte da iniciação do tempo integral na escola [...] isso foi contra tudo que a gente fazia. Porque no início vinha aquela angústia de como fazer, falta isso, falta aquilo, mas o prefeito, com toda aquela coragem, aquele entrosamento dele, dizia: vamos enfrentar porque vai dar certo! Pode falhar alguma coisa no início, lógico. E ele falava: "vamos correr". Mas até hoje acontecem algumas dificuldades, mas são assim algo que pode ser mediado no mesmo tempo, e sanado porque a gente agora já tem mais experiência (MINISTÉRIO DA EDUCAÇÃO, UFPR, 2010, p. 24).

Os técnicos destacam que foram muito estimulados pelo prefeito e com isso enfrentaram os desafios de aprender a fazer um trabalho novo, para o qual não havia um caminho já traçado, e que era muito desafiador. Esse depoimento destaca a importância do engajamento dos gestores municipais: prefeito e secretário de desenvolvimento humano para o sucesso do Projeto de Tempo Integral.

Tomando por base a experiência do município de Apucarana, alguns aspectos importantes da proposta de educação em tempo integral foram levantados e dentre eles se poderiam destacar como avanços:

A presença da comunidade nos espaços escolares pode ser considerada um aspecto normal nos cotidianos escolares, todavia, nessa experiência foi possível notar uma intensificação da participação da comunidade em diversos momentos, inclusive no planejamento das atividades pedagógicas. Em função dos objetivos pretendidos pela proposta de educação em tempo integral, certamente a experiência agrega novas perspectivas ao próprio sentido da escola e seu papel social e comunitário.

Em decorrência desse primeiro aspecto destacado, se poderia dizer que o repensar do papel e das funções que desempenham os professores, as famílias, os gestores públicos ou os gestores escolares, anuncia um novo fenômeno no campo 
educativo, e, como tal, merece um olhar pedagógico para sua melhor compreensão.

$\mathrm{O}$ fato de ter sido um projeto implantado em toda a rede municipal e contar com o apoio de várias instâncias favoreceram o sucesso de diversos aspectos pedagógicos e administrativos.

A preocupação latente entre professores, gestores e coordenadores pedagógicos com a qualificação do tempo vivido pelos estudantes em sua permanência na escola denota que mais que a ampliação quantitativa do tempo, também existiu uma preocupação em dar significado às novas vivências escolares dos estudantes.

A tentativa de superação do uso da expressão "contraturno" pode ser considerada como um avanço positivo, pois, fazendo uso das palavras do Secretário, já "não existe mais essa divisão em dois turnos, em que parecem duas escolas, uma escola séria e a escola da brincadeira. Tudo é escola e em várias unidades temos mesclado um pouco a divisão das oficinas com as disciplinas curriculares" (MINISTÉRIO DA EDUCAÇÃO, UFPR, 2010, p. 37).

E como possíveis desafios para o desenvolvimento da proposta, se poderia apontar:

1. a demanda de diversificação das atividades escolares/oficinas e a integração à proposta formativa geral das escolas, porque as propostas são ainda bastante vinculadas ao que o professor pode ou consegue oferecer, sendo, em alguns casos, as atividades artesanais utilizadas como alternativa.

2. A falta de melhor estrutura física das escolas, pois a ampliação da jornada escolar e a diversificação das atividades demandam outros espaços de trabalho para professores e alunos. Por outro lado: "É preciso considerar que nesse sentido foi positivo o fato de que nessa experiência a ideia da educação integral foi construída com as comunidades e paralelamente foi-se construindo e adaptando os espaços para isso"(MINISTÉRIO DA EDUCAÇÃO, Estudo Qualitativo, 2010).

3. Necessidade de continuidade da ampliação da jornada escolar para crianças que saem do $5^{\circ}$ ano e vão para uma escola em tempo parcial. Nesse sentido, também vale destacar a necessidade de articulação entre as redes municipal e estadual de ensino para ofertar aos alunos a possibilidade de continuarem a ter uma .

4. A preocupação com uma avaliação interna - realizada pela própria rede - sobre o desempenho educacional dos alunos, uma vez que o 
IDEB é um índice indicativo apenas das áreas de Língua Portuguesa (leitura - interpretação textual - e Matemática). Seria importante saber quais outras áreas foram desenvolvidas e quanto para se estabelecer a real contribuição do Tempo Integral.

A implementação da lei federal $n^{\circ} 11.738 / 2008$ que instituiu o piso salarial profissional do magistério público da educação básica e que também acena para um padrão de 40 horas para ser cumprido em uma mesma escola, bem como a hora permanência ( $1 / 3$ das 40 horas) dedicadas a estudos e planejamento dos professores para garantir maior dedicação à escola e também mais tempo para estudar e planejar as atividades pedagógicas pode se constituir em grande avanço para a Educação Integral.

\section{REFERÊNCIAS}

COELHO, L. M. C. da C.; CAVALIÈRE, A. M. V. Educação brasileira e(m) tempo integral. Petrópolis: Vozes, 2002.

ÉBOLI, T. Uma experiência de Educação Integral. Rio de Janeiro: Fundação Getúlio Vargas, 1969.

FERNÁNDEZ ENGUITA, M. La jornada escolar. Análisis y valoración de los procesos, los efectos y las opciones de la implantación de la jornada continua. Barcelona: Ariel, 2001.

MINISTÉRIO DA EDUCAÇÃO. Educação Integral/Educação Integrada e(m) tempo integral: concepções e práticas na educação brasileira. Mapeamento das experiências de jornada escolar ampliada no Brasil. Estudo qualitativo, 2010. Disponível em: $<$ http:// www.mec.gov.br/seb/maiseducação/documentos >. Acesso em: 20/6/2011.

MINISTÉRIO DA EDUCAÇÃO. Educação Integral/ Educação Integrada e(m) tempo integral: concepções e práticas na educação brasileira. Mapeamento das experiências de jornada escolar ampliada no Brasil: estudo qualitativo. Relatório Integral da Região Sul./UFPR, 2010.

PREFEITURA DE PORTO ALEGRE. Disponível em: $<$ http://www2.portoalegre.rs.gov. br/smed $>$. Acesso em: 17/1/2008.

TEIXEIRA, Anísio. Por que "escola nova”? Bahia: Livraria e Typografia do Comércio, 1930.

Texto recebido em 12 de março de 2012.

Texto aprovado em 05 de abril de 2012. 
